\title{
Modelling the Impact and Effects of Climatic Variability on Electricity Energy Consumption in the Yendi Municipality of Ghana
}

\author{
Wahab A. Iddrisu1, Sampson T. Appiah'1, Khalid Abdul-Mumin1', Abdul-Rahman Abdul-Samed ${ }^{2}$ \\ ${ }^{1}$ Department of Mathematics and Statistics, University of Energy and Natural Resources, Sunyani, Ghana \\ ${ }^{2}$ Department of Statistics, Tamale Technical University, Tamale, Ghana \\ Email: iddrisu.wahab@uenr.edu.gh
}

How to cite this paper: Iddrisu, W.A., Appiah, S.T., Abdul-Mumin, K. and Abdul-Samed, A.-R. (2020) Modelling the Impact and Effects of Climatic Variability on Electricity Energy Consumption in the Yendi Municipality of Ghana. Open Journal of Energy Efficiency, 9, 1-13.

https://doi.org/10.4236/ojee.2020.91001

Received: January 3, 2020

Accepted: March 1, 2020

Published: March 4, 2020

Copyright $\odot 2020$ by author(s) and Scientific Research Publishing Inc. This work is licensed under the Creative Commons Attribution International License (CC BY 4.0).

http://creativecommons.org/licenses/by/4.0/

(c) (i) Open Access

\begin{abstract}
One of the cherished assets of every economy is electricity since it has proven to be the major source of energy for industrialization. Developing economies like Ghana have suffered the downside of poor management of the already inadequate electrical energy at its disposal. This is as a result of limited research into factors that influences electricity energy consumption, most importantly, the effects of climatic variables on electricity energy consumption. This research work explores the causal connection between climatic variables and electricity energy consumption, and develops a Vector Auto Regression (VAR) model to determine the influence of the climatic variables in forecasting electricity energy consumption in Yendi Municipality in the northern region of Ghana. The climatic factors considered in this work are; Rainfall (Rain), maximum temperature $\left(\mathrm{T}_{\max }\right)$, Sunshine (Sun), Wind (wind) and Relative Humidity (RH). The Granger causality tests employed in this work revealed that aside from Relative Humidity, the end energy consumption is affected by the other four climatic factors under consideration. The impulse response was used to ascertain the active interaction among electricity energy consumption and the climatic variables. The impulse response of electricity energy consumption to the climatic variables indicates a maximum positive effect of Temperature and Sunshine on electricity energy consumption in March and September respectively. The VAR model was also used in forecasting future consumption of electricity energy. The results indicate excellent forecasts of electricity energy consumption for the first four months of 2019.
\end{abstract}

\section{Keywords}

Electricity Energy Consumption, Vector Autoregression, Climatic Variables 


\section{Introduction}

Electricity is the main source of energy that propels the industrial sector of every economy. Developing countries such as Ghana experience energy management drawbacks as a result of restricted and uncorrelated research in the area to assist residents and private stakeholders with the evidence they need to make informed investment choices [1]. This study seeks to explore the impact and effects of climatic variability on electricity energy consumption in the Yendi municipality of Ghana.

In Ghana, as a developing nation, power request has been generally low, in spite of the fact that, as of late, request has been ascending because of urbanization, expansion in monetary development and modern exercises.

Accomplishing general access to electricity by 2020 is a responsibility Ghana is resolved to achieve since 1989 with the foundation of the National Electrification Scheme [2]. The National Electrification Scheme (NES) which is one of Ghana's priority projects, works as the ultimate instrument driving the endeavors to extended electricity to all corners of the nation over a multi-year time frame from 1990-2020. Towards the beginning of the framework, just $15 \%-20 \%$ of Ghana's populace had power [3].

Late power access surveys have put access rates at 66.7 percent in $2009,80.51$ percent in 2015 and 82.5 percent in 2016 [3]. These figures show a yearly increment in power access pace of 2.60 percent. Because of current circumstances, Ghana is probably going to miss its objective of succeeding all-inclusive access to power continuously by 2020 .

According to [4], the impacts of environmental modification are anticipated in the United States and parts of the world. There will be changes in regular examples and precipitation sums because of ascends in normal temperatures in many areas, which assist adjustments in the force and example of outrageous climate occasions, and ocean level ascent. Energy creation and use are clear ramifications portion of these impacts have. For example, normal warming can be relied upon to expand energy. These are necessities for cooling and diminish energy prerequisites for warming.

As per certified cloud security professional (CCSP), change in climatic variables has more noteworthy effects that could change the discernments and valuations of energy innovation options. These impacts could help in planning energy arrangements, choice makings, and foundations. The dependence on non-renewable energy sources for power generation together with relatively high electricity dependence from warming and cooling equipment increases the vulnerability of several nations, including Ghana to climate change [5]. The observational assessments of atmosphere affectability to the energy part are utilized to anticipate the expense of environmental change adjustments. Scope of changes in temperature, precipitation, and other atmosphere measures can be foreseen by models related to atmosphere variables [6]. These atmospheric models foresee a huge increment in worldwide normal temperatures before the end of the present century. 
There is emerging literature examining the weather and climate response of electricity energy consumption [7]. The electricity we all know is a comfort providing energy and as weather conditions change, humans by nature will still want to cling to the favorable conditions they have been living in despite the changes the new weather brings along. They attempt to accomplish this by utilizing various machines and devices to adjust the limitations the climate accompanies. While remaining at home, individuals will all the more widely utilize nearby amusement gadgets, for example, television, radio, and personal computers.

Then again, the consumption of machines, for example fans, ice chests, and iceboxes are likewise observed to be high when the climate is dry and bright. The temperature on the Earth's surface is brought about by sun-based energy. Consequently, a cozy relationship, ought to be between sun-based presentation and temperature. Any adjustment in temperature prompts a difference in water vanishing, causing the adjustment in dampness. Moreover, the breeze speed changes, because of distinctions in temperature prompted by air development. On the whole, temperature may be seen as the most overarching climatic variable that has the most significant effect on electricity energy consumption [7]. This paper there aims at establishing the relationship between climatic variables including temperature, and electricity energy consumption.

\section{Methodology}

\subsection{Model}

The vector autoregressive (VAR) model, used for the analysis of the effects of climatic variability on electricity energy consumption, can be specified as follows:

$$
y_{t}=A_{1} y_{t-1}+A_{2} y_{t-2}+\cdots+A_{p} y_{t-p}+C D_{t}+u_{t}
$$

where $y_{t}=\left(E E C, R H, T_{\max }\right.$, Wind, Sun, Rain $)$ is a vector of 6 observable endogenous variables namely electricity energy consumption (EEC), Relative Humidity (RH), Maximum Temperature ( $\mathrm{T}_{\max }$ ), Wind, Sunshine (Sun) and Rainfall (Rain). $D_{t}$ comprises all deterministic Variables, $u_{t}$ is a K-dimensional unobservable zero mean white noise process, $A_{i} ; i=1, \cdots, p$ and $C$ are constraint matrices.

\subsection{Structural Analysis}

The general model of $\operatorname{VAR}(p)$ has many parameters, and due to complex connections and reaction between the variables in the model, they may be difficult to interpret [8]. As a consequence, numerous types of structural study are often used to summarize the complex properties of a VAR. The 3 main types of operational analysis summaries include Granger causality tests, impulse response functions and forecast error variance decomposition.

\subsection{Mean Absolute Percentage Error}

The accurateness of forecasts produced by the fitted VAR model was determined using mean absolute percentage error (MAPE) given below: 


$$
M A P E=\left(\frac{1}{T} \sum_{t=1}^{T}\left|\frac{F_{t}-Y_{t}}{Y_{t}}\right|\right) \times 100
$$

where $T$ is the number of forecasts, $F_{t}$ and $Y_{t}$ are the predicted and observed values respectively.

\section{Results}

\subsection{Description of the Data}

Monthly climatic data on rainfall (Rain), maximum temperature $\left(T_{\max }\right)$, Sunshine (Sun), Wind (wind) and Relative Humidity (RH) from January 2008 to December 2018 were obtained from the Ghana Meteorological Agency while data on electricity energy consumption (EEC) for the same period was acquired from the Volta River Authority (VRA). Table 1 presents descriptive statistics for the variables considered.

The time series plots of the original data are shown in Figure 1, which revealed that both electricity energy consumption and the climatic variables in

Table 1. Descriptive statistics for all variables considered.

\begin{tabular}{ccccccc}
\hline & EEC & $\mathrm{T}_{\text {Max }}$ & RH & Rain & Sunshine & Wind \\
\hline Maximum & 20.50 & 39.90 & 100.25 & 318.2 & 9.900 & 88.50 \\
Minimum & 6.70 & 26.50 & 6.07 & 0.0 & 4.100 & 20.50 \\
Mean & 11.47 & 34.09 & 46.50 & 106.8 & 7.502 & 61.34 \\
Median & 10.00 & 34.60 & 44.39 & 93.9 & 7.850 & 67.25 \\
\hline
\end{tabular}
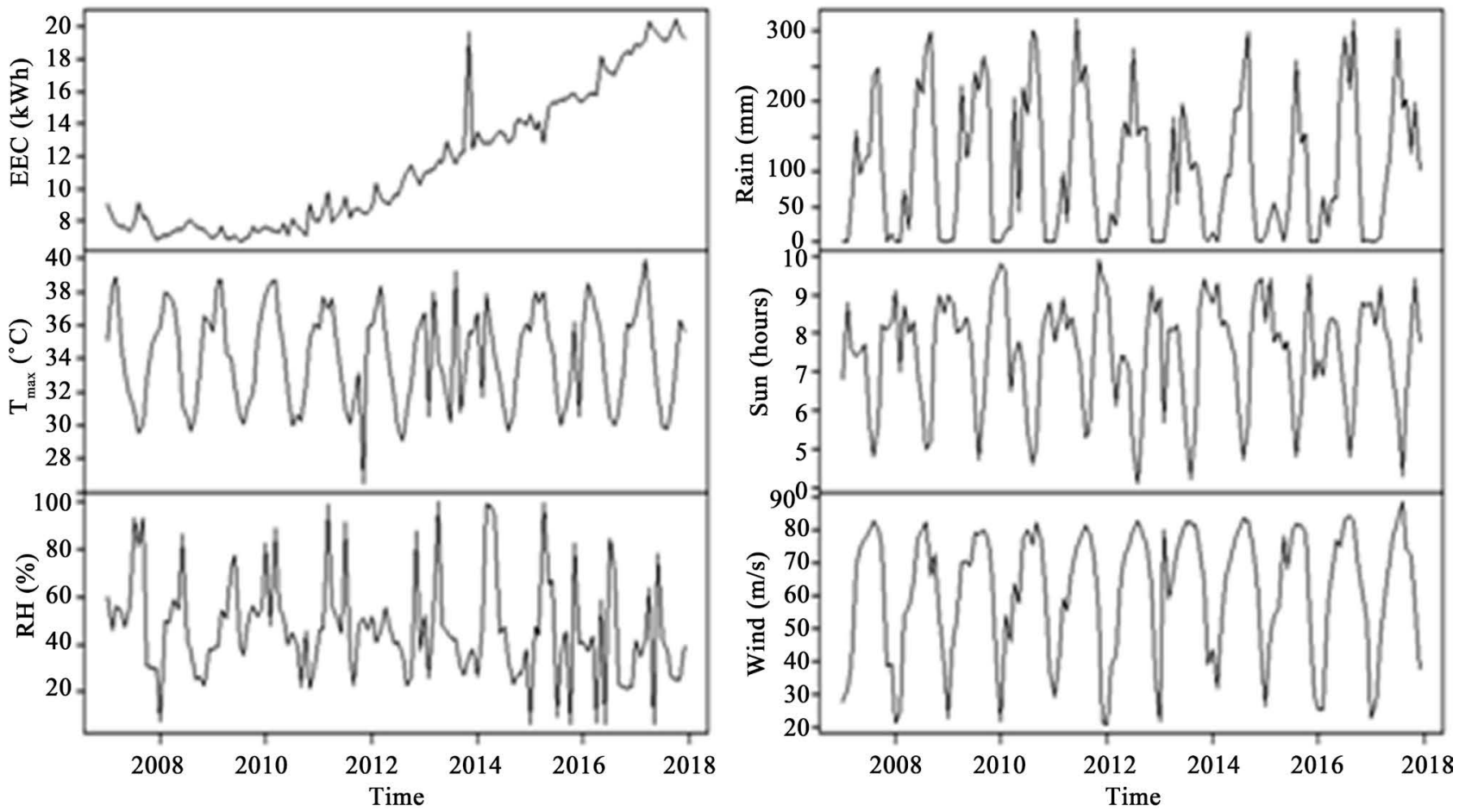

Figure 1. Time series plots of electricity energy consumption and climatic variables. 
the Yendi Municipality from 2008 to 2018 have been largely non-stationary. This is as a result of the presence of irregularities, trends, and seasonality. The mean is not constant throughout the successions.

However, stationarity in both electricity energy consumption and the climatic variables was achieved by computing the first difference of the original data as shown in Figure 2 below.

To confirm the stationarity observed in Figure 2, each of the variables in the differenced data was tested for the presence of a unit root using a test suggested by Dickey and Fuller [9]. The Augmented Dickey-Fuller (ADF) test is a unit root test for stationarity. The null hypothesis for the ADF test is that there is a unit root while the alternate hypothesis varies as per the condition applied.

Results of the ADF tests, presented in Tables 2(a)-(c), rejected the assumption of a unit root for all time series considered, implying that the relationships among the various variables analyzed below are not spurious.

\subsection{VAR Estimation Results}

A vector autoregressive model of the monthly electricity energy consumption and climatic variables was estimated with 3 lags for each variable in each equation. Each equation has $6 \times 3$ unrestricted coefficients plus one coefficient for a constant and one for a trend. The number of lags was chosen based on four tests: the Final Prediction Error (FPE) test [10], the Hannan Quinne (HQ) test [11], and the Information Criteria suggested by Akaike (AIC) [12] and by Schwarz (SC) [13]. These measures are defined such that the smaller the better. Two out of the four tests (HQ and FPE) indicated that as many as 3 lagged monthly values
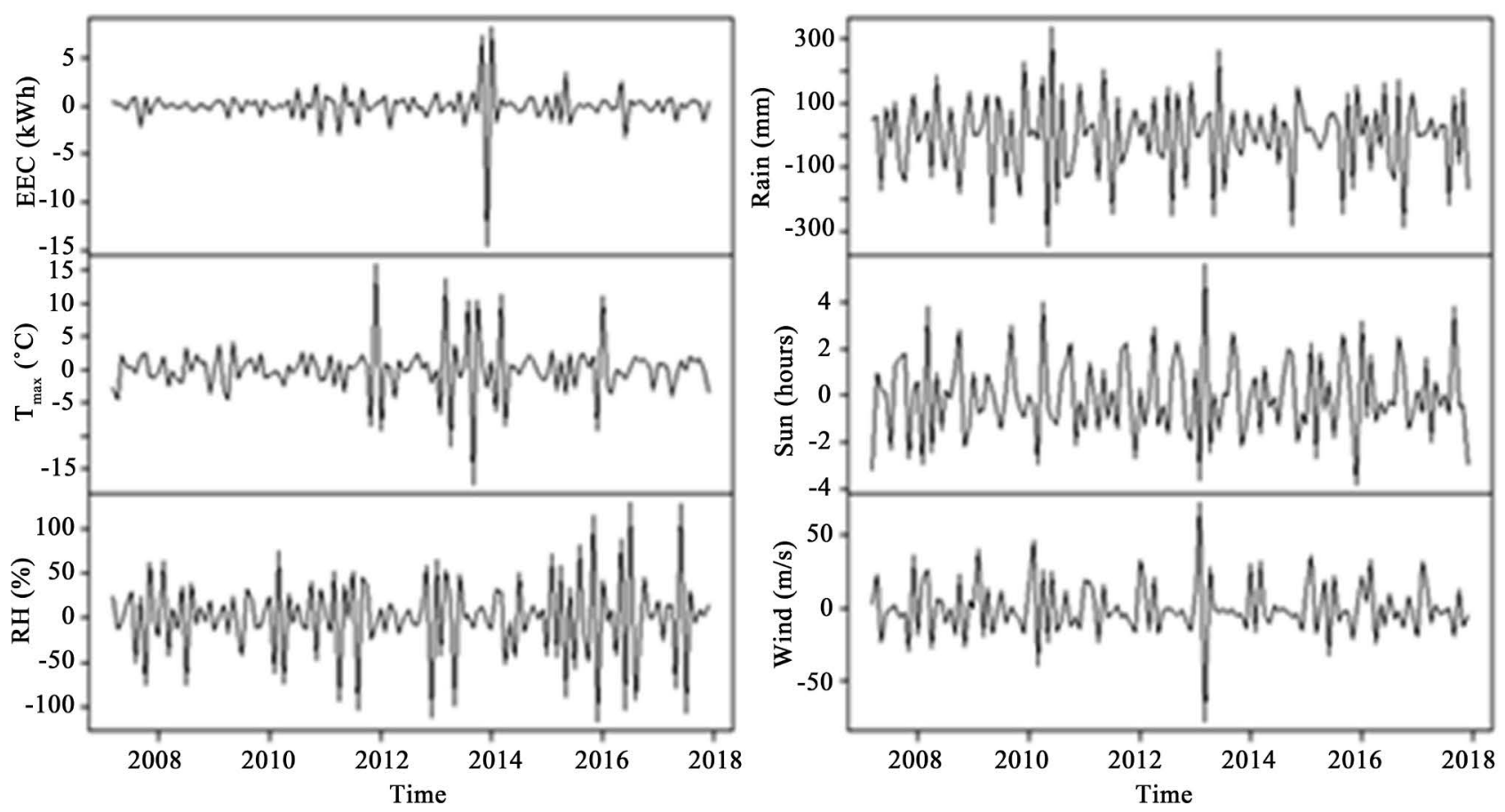

Figure 2. Time series plots of first difference in electricity energy consumption and the climatic variables. 
Table 2. (a) ADF unit root test for electricity energy consumption and maximum temperature; (b) ADF unit root test for relative humidity and sunshine; (c) ADF unit root test for rainfall and wind.

(a)

\begin{tabular}{ccccccc}
\hline & \multicolumn{3}{c}{ EEC } & & \multicolumn{3}{c}{$\mathrm{T}_{\max }$} \\
\cline { 2 - 7 } & Tau3 & Phi2 & Phi3 & Tau3 & Phi2 & Phi3 \\
\hline Test statistic & -3.258 & 4.7284 & 5.9942 & -7.2759 & 17.6673 & 26.5006 \\
1 Pct. & -3.99 & 6.22 & 8.43 & -3.99 & 6.22 & 8.43 \\
5 Pct. & -3.43 & 4.75 & 6.49 & -3.43 & 4.75 & 6.46 \\
10 Pct. & -3.13 & 4.07 & 5.47 & -3.13 & 4.07 & 5.47 \\
\hline
\end{tabular}

(b)

\begin{tabular}{ccccccc}
\hline & \multicolumn{3}{c}{ RH } & \multicolumn{3}{c}{ Sun } \\
\cline { 2 - 7 } & Tau3 & Phi2 & Phi3 & Tau3 & Phi2 & Phi3 \\
\hline Test statistic & -6.5368 & 14.2455 & 21.3647 & -7.1893 & 17.243 & 25.8651 \\
1 Pct. & -3.99 & 6.22 & 8.43 & -3.99 & 6.20 & 8.43 \\
5 Pct. & -3.43 & 4.75 & 6.49 & -3.43 & 4.75 & 6.46 \\
10 Pct. & -3.13 & 4.07 & 5.47 & -3.13 & 4.07 & 5.47 \\
\hline
\end{tabular}

(c)

\begin{tabular}{ccccccc}
\hline & \multicolumn{3}{c}{ Rain } & \multicolumn{3}{c}{ Wind } \\
\cline { 2 - 7 } & Tau3 & Phi2 & Phi3 & Tau3 & Phi2 & Phi3 \\
\hline Test statistic & -5.8646 & 11.486 & 17.2198 & -5.684 & 10.8368 & 16.2539 \\
1 Pct. & -3.99 & 6.22 & 8.43 & -3.99 & 6.22 & 8.43 \\
5 Pct. & -3.43 & 4.75 & 6.49 & -3.43 & 4.75 & 6.46 \\
10 Pct. & -3.13 & 4.07 & 5.47 & -3.13 & 4.07 & 5.47 \\
\hline
\end{tabular}

may be sufficient. The AIC and SC suggested 12 and 1 lags respectively. Hence, based on HQ and FPE, the optimal lag length used was 3 (Table 3 ).

Table 4 contains parameter estimates of the fitted VAR (3) model. While some of the parameters are significant at the 0.05 level, others are not. However, for a VAR model, much more information is rather obtained from the structural analysis presented in the next sub-sections.

\subsection{Granger Causality Test}

Granger-causality test is a basic approach used to find out whether a specific variable is influenced by developments in different variables [14]. A significant bit of leeway of this test is that they are not influenced by the ordering of the VAR framework. The results of the Granger causality test presented in Table 5 indicate that maximum temperature, rainfall, sunshine and wind all Granger causes electricity energy consumption. The only climatic variable that does not Granger causes electricity energy consumption in the Yendi municipality of Ghana is relative humidity. 
Table 3. Optimal lag length selection.

\begin{tabular}{ccccc}
\hline Lag & AIC & HQ & SC & F PE \\
\hline 1 & $2.427510 \mathrm{e}+01$ & $2.486940 \mathrm{e}+01$ & $2.573853 \mathrm{e}+01$ & $3.494602 \mathrm{e}+10$ \\
2 & $2.382875 \mathrm{e}+01$ & $2.488529 \mathrm{e}+01$ & $2.643041 \mathrm{e}+01$ & $2.257096 \mathrm{e}+10$ \\
3 & $2.329940 \mathrm{e}+01$ & $2.481818 \mathrm{e}+01$ & $2.703928 \mathrm{e}+01$ & $1.359543 \mathrm{e}+10$ \\
4 & $2.328844 \mathrm{e}+01$ & $2.526947 \mathrm{e}+01$ & $2.955389 \mathrm{e}+01$ & $1.402660 \mathrm{e}+10$ \\
5 & $2.353755 \mathrm{e}+01$ & $2.598081 \mathrm{e}+01$ & $2.955389 \mathrm{e}+01$ & $1.928749 \mathrm{e}+10$ \\
6 & $2.344247 \mathrm{e}+01$ & $2.634797 \mathrm{e}+01$ & $3.059703 \mathrm{e}+01$ & $1.948801 \mathrm{e}+10$ \\
7 & $2.303484 \mathrm{e}+01$ & $2.640258 \mathrm{e}+01$ & $3.132763 \mathrm{e}+01$ & $1.509671 \mathrm{e}+10$ \\
8 & $2.300900 \mathrm{e}+01$ & $2.683897 \mathrm{e}+01$ & $3.244001 \mathrm{e}+01$ & $1.820338 \mathrm{e}+10$ \\
9 & $2.311038 \mathrm{e}+01$ & $2.740259 \mathrm{e}+01$ & $3.367961 \mathrm{e}+01$ & $2.697565 \mathrm{e}+10$ \\
10 & $2.261599 \mathrm{e}+01$ & $2.737044 \mathrm{e}+01$ & $3.432345 \mathrm{e}+01$ & $2.445369 \mathrm{e}+10$ \\
11 & $2.209266 \mathrm{e}+01$ & $2.730935 \mathrm{e}+01$ & $3.493835 \mathrm{e}+01$ & $2.480023 \mathrm{e}+10$ \\
12 & $2.098001 \mathrm{e}+01$ & $2.665894 \mathrm{e}+01$ & $3.496392 \mathrm{e}+01$ & $1.701365 \mathrm{e}+10$ \\
\hline & & & & \\
\hline & & 2.3010 & & \\
\hline
\end{tabular}

Table 4. Parameter estimates.

\begin{tabular}{|c|c|c|c|c|}
\hline & Estimate & Std. Error & T-Value & $\operatorname{Pr}(>/ \mathrm{t})$ \\
\hline EECS 1 & 0.3494530 & 0.0886472 & 3.942 & 0.000143 \\
\hline $\mathrm{T}_{\max } 1$ & -0.0160955 & 0.0501926 & -0.321 & 0.749070 \\
\hline RH 1 & 0.0018506 & 0.0041097 & 0.450 & 0.653397 \\
\hline Rain 1 & -0.0005926 & 0.0014433 & -0.411 & 0.682200 \\
\hline Sun 1 & 0.0345915 & 0.0920564 & 0.376 & 0.707822 \\
\hline Wind 1 & -0.0020459 & 0.0092662 & -0.221 & 0.825667 \\
\hline EECS 2 & 0.3399468 & 0.0854443 & 3.979 & 0.000125 \\
\hline $\mathrm{T}_{\max } 2$ & -0.0799863 & 0.0477015 & -1.677 & 0.096445 \\
\hline RH 2 & 0.0034133 & 0.0039992 & 0.853 & 0.395258 \\
\hline Rain 2 & 0.0034133 & 0.0039992 & -1.888 & 0.061746 \\
\hline Sun 2 & -0.2994379 & 0.1015187 & -2.950 & 0.003895 \\
\hline Wind 2 & -0.0106990 & 0.0093065 & -1.150 & 0.252813 \\
\hline EECS 3 & 0.1538409 & 0.0845139 & 1.820 & 0.071457 \\
\hline $\mathrm{T}_{\max } 3$ & 0.1970079 & 0.0483835 & 4.072 & $8.87 e-05$ \\
\hline RH 3 & -0.0005666 & 0.0039238 & -0.144 & 0.885454 \\
\hline Rain 3 & 0.0009670 & 0.0016534 & 0.585 & 0.559827 \\
\hline Sun 3 & -0.2085310 & 0.1056462 & -1.974 & 0.050928 \\
\hline Wind 3 & 0.0071379 & 0.0084644 & 0.843 & 0.400916 \\
\hline Const. & 1.1393936 & 2.9196352 & 0.390 & 0.697112 \\
\hline Trend & 0.0194696 & 0.0061675 & 3.157 & 0.002063 \\
\hline
\end{tabular}




\subsection{Impulse Response}

Impulse response analysis was used to analyze the active relations between electricity energy consumption and the climatic variables of the VAR (3) process. The impulse responses of electricity energy consumption to climatic variables are shown in Figures 3-7. The response of electricity energy consumption to some of the climatic variables has a clear fluctuation; there is a peak positive effect

Table 5. Granger causality test.

\begin{tabular}{ccccc}
\hline Cause Variable & Null hypothesis & F-Value & P-Value & Decision \\
\hline $\mathrm{T}_{\max }$ & Does not Granger-cause EEC & 3.5004 & $8.25 \mathrm{e}-06$ & Reject the null hypothesis \\
Rain & Does not Granger-cause EEC & 2.9847 & $2.98-07$ & Reject the null hypothesis \\
$\mathrm{RH}$ & Does not Granger-cause EEC & 0.9311 & 0.5232 & Fail to reject the null Hypothesis \\
Sun & Does not Granger-cause EEC & 5.6072 & $7.28 \mathrm{e}-11$ & Reject the null hypothesis \\
Wind & Does not Granger-cause EEC & 4.0056 & $5.44 \mathrm{e}-07$ & Reject the null hypothesis \\
\hline
\end{tabular}

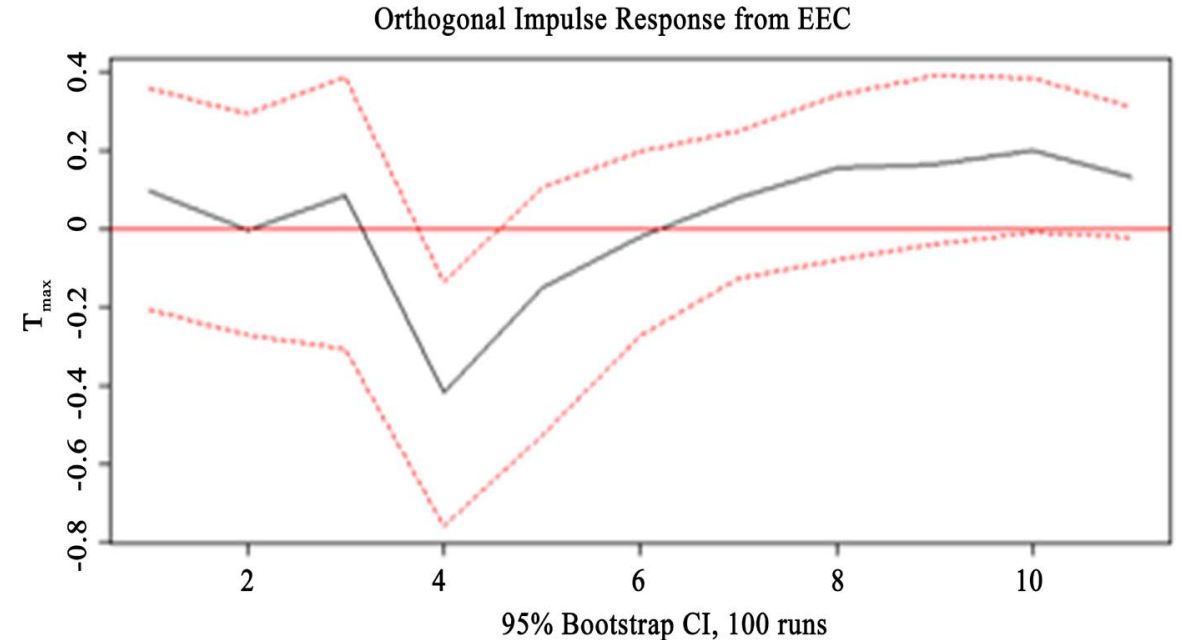

Figure 3. Impulse response of maximum temperature.

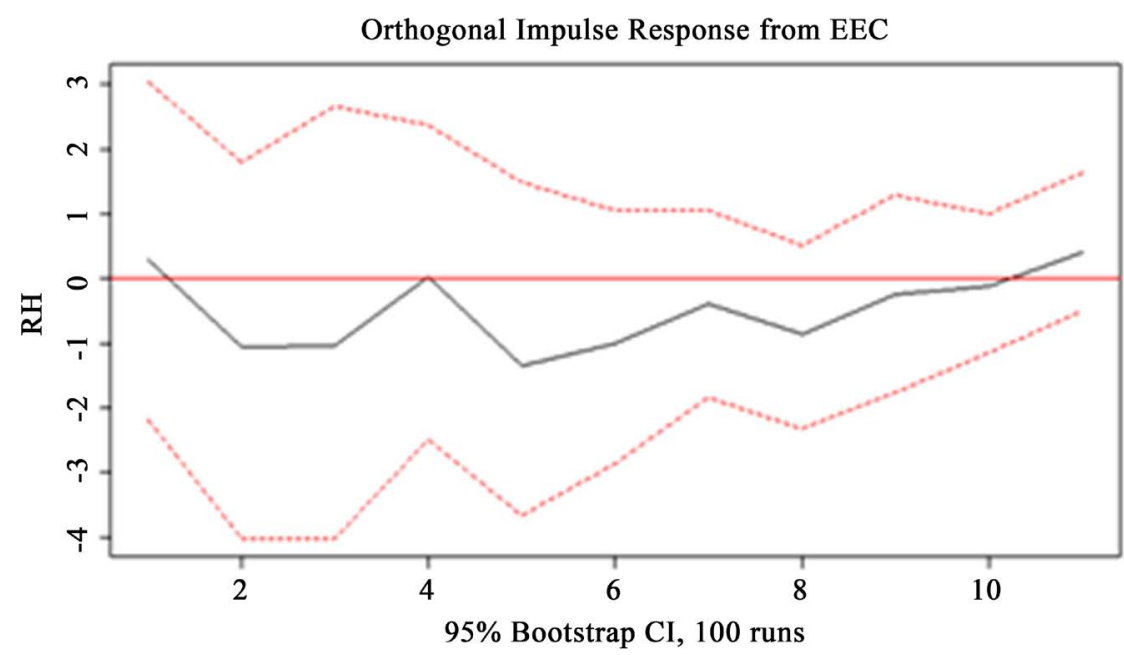

Figure 4. Impulse response of relative humidity. 


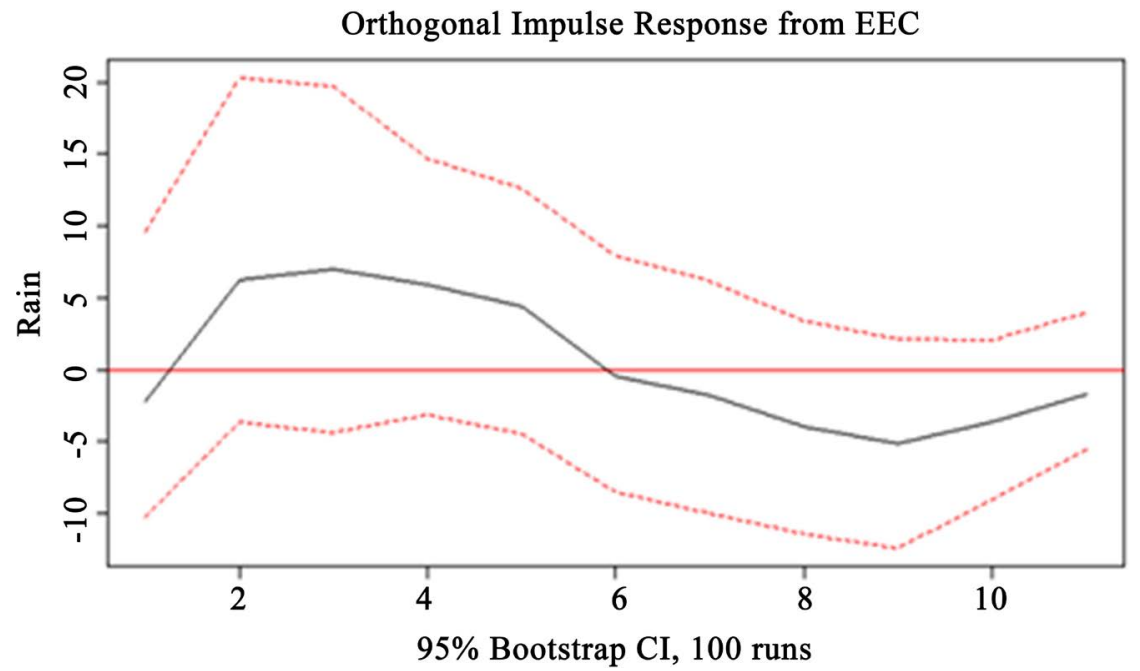

Figure 5. Impulse response of rainfall.

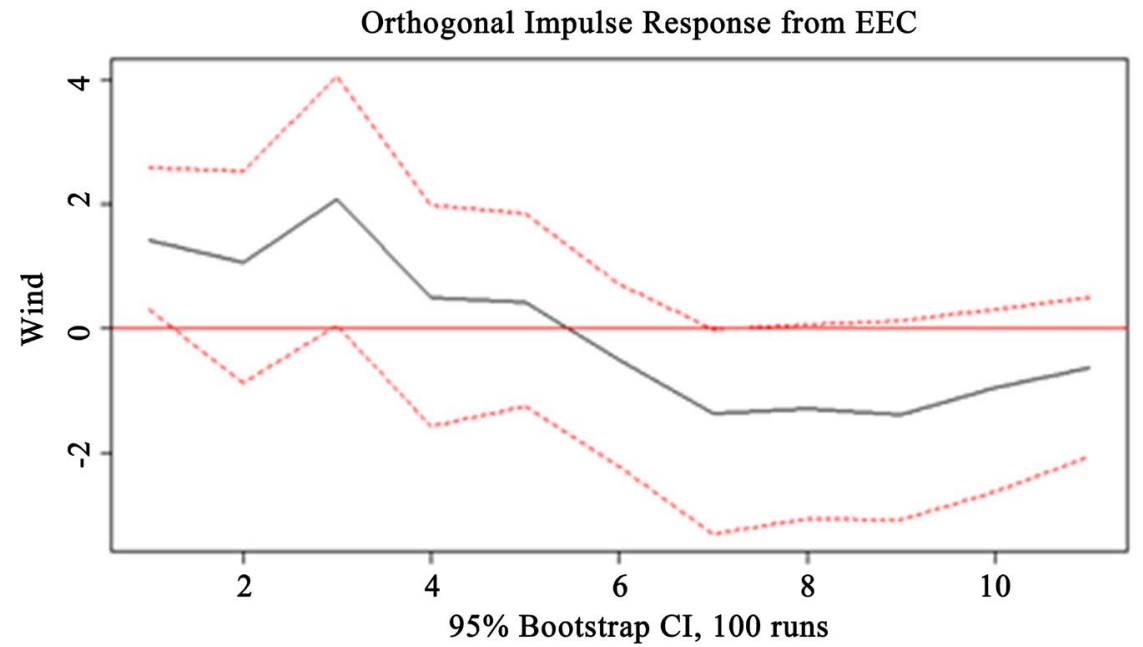

Figure 6. Impulse response of wind.

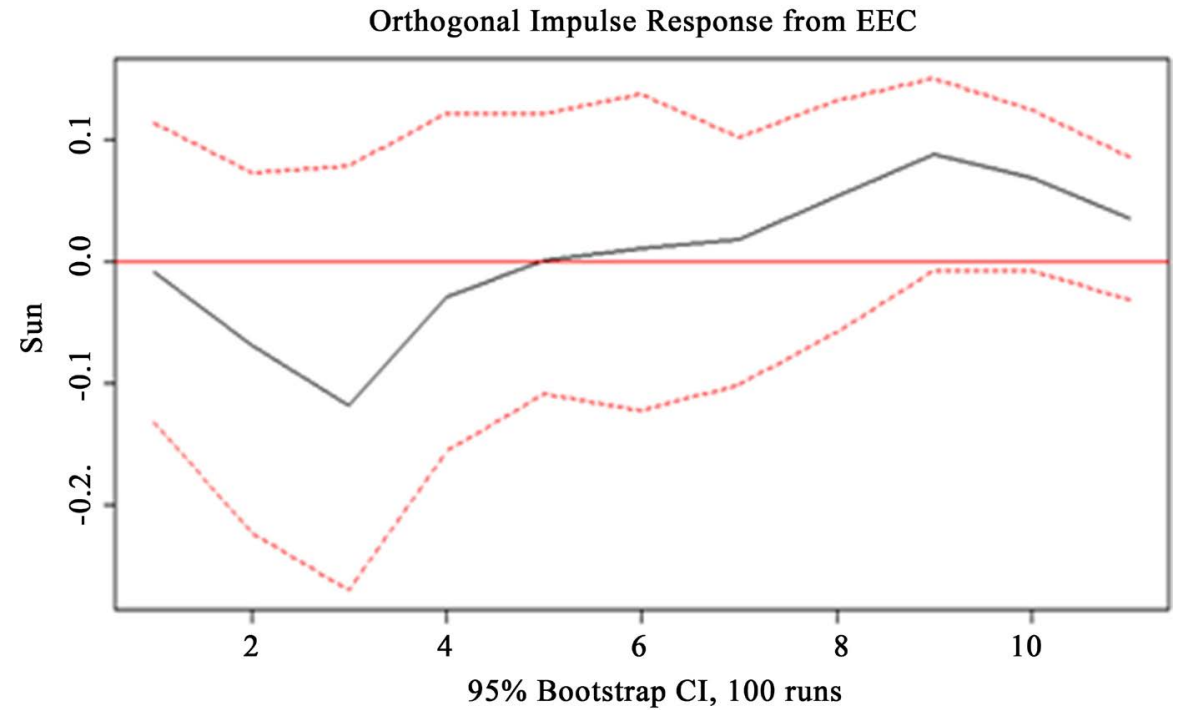

Figure 7. Impulse response of sun. 
of maximum temperature on electricity energy consumption in March ( $3^{\text {rd }}$ month) and lowermost adverse effect of maximum temperature on electricity energy consumption in April (Figure 3). Also, the peak positive effect of sunshine on electricity energy consumption is observed in September ( $9^{\text {th }}$ month) while the lowest negative effect of sunshine on electricity energy consumption is observed in March (Figure 3). The response of electricity energy consumption to relative humidity, rainfall and wind did not show obvious fluctuations (Figures 4-6) have less effect almost throughout the year.

\subsection{Decomposition of Variance and Residual Correlations}

Forecast error variance decomposition (FEVD) is well-known in interpreting VAR models. Outcome of the FEVD for both electricity energy consumption and the climatic factors are shown in Figure 8 and Table 6 . The results indicate that, an average of $67.15 \%$ of the pattern of the variability in the electricity energy consumption has been explained by innovations in electricity energy consumption in the past, to a large extent, about $12.13 \%$ of the pattern of the variability in the electricity energy consumption has been explained by past developments in maximum temperature, about $11.15 \%$ of the trend of the variability in

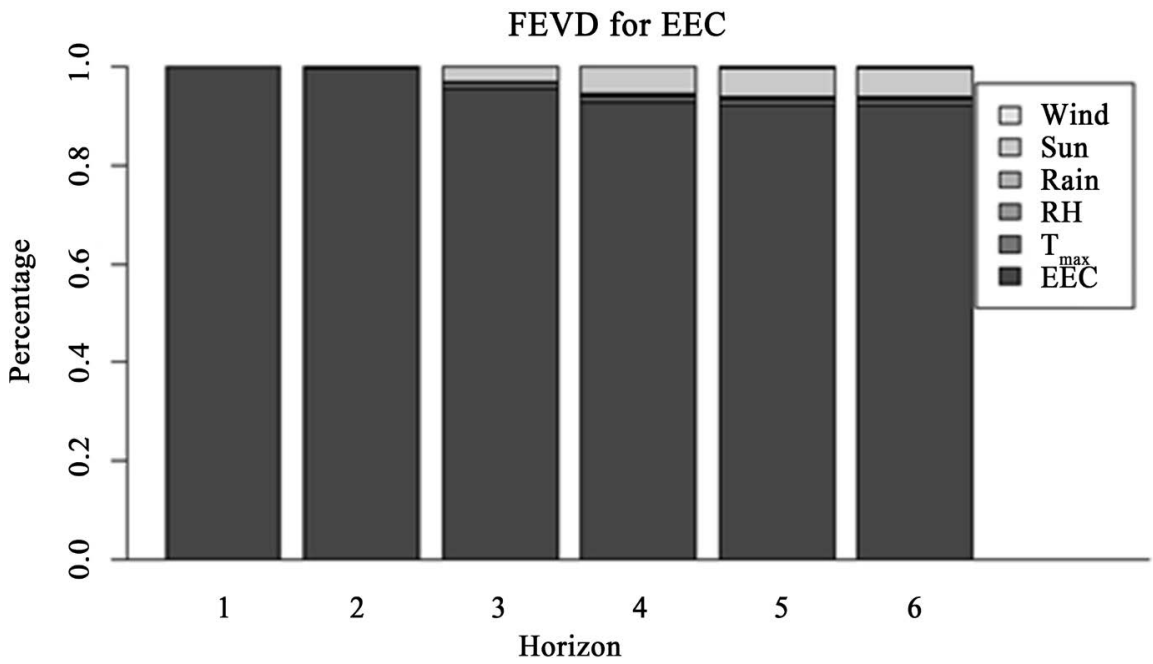

Figure 8. Forecast error decomposition.

Table 6. Forecast error decomposition.

\begin{tabular}{|c|c|c|c|c|c|c|}
\hline & EECS & $\mathrm{T}_{\max }$ & $\mathrm{RH}$ & Rain & Wind & Sun \\
\hline 1 & 1.0000000 & $0.000000 \mathrm{e}+00$ & 0.000000000 & 0.00000000 & 0.000000000 & 0.0000000000 \\
\hline 2 & 0.9950297 & $4.978732 \mathrm{e}-05$ & 0.001680660 & 0.00179096 & 0.001118383 & 0.0003304903 \\
\hline 3 & 0.9008066 & $1.134592 \mathrm{e}-02$ & 0.003249070 & 0.03912292 & 0.036597644 & 0.0088778243 \\
\hline 4 & 0.8470005 & $2.619592 \mathrm{e}-02$ & 0.002798364 & 0.03336878 & 0.081594559 & 0.0090419108 \\
\hline 5 & 0.8303465 & $2.567041 \mathrm{e}-02$ & 0.002641039 & 0.04150123 & 0.091420320 & 0.0084204838 \\
\hline 6 & 0.8381792 & $2.338709 \mathrm{e}-02$ & 0.003465641 & 0.03900386 & 0.087599230 & 0.0083650207 \\
\hline
\end{tabular}


electricity energy consumption is explained by innovations in the past sunshine, $5.25 \%$ of the trend of the variability in electricity energy consumption is explained by past innovations in wind, $1.20 \%$ of the trend of the variability of electricity energy consumption is explained by past inventions of rainfall, while $1.12 \%$ of the trend of the variability in electricity energy consumption is explained by past innovations in relative humidity.

\subsection{Electricity Energy Consumption Forecast}

Forecasting is one of the principal motivations behind multivariate time-series studies. The VAR (3) model developed can be utilized as a prescient framework for making a forecast of electricity energy consumption. The forecasts of the differenced electricity energy consumption for the first 6 months of 2019 are shown in Figure 9 and Table 7. These forecasts indicate an increasing trend of electricity energy consumption in the Yendi Municipality in Northern Ghana.

\subsection{Forecast Accuracy}

The mean absolute percentage error (MAPE) gives an indication of the average size of forecasting error stated as a percentage of the relevant observed value irrespective of whether the forecasting error is positive or negative [15]. Using data from January 2019 to April 2019, the MAPE for the fitted model is obtained to be $4.54 \%$ (Table 8) using Equation (11), which is a sign of potentially excellent forecasts by the fitted VAR (3) model [15].

Forecast of series EEC

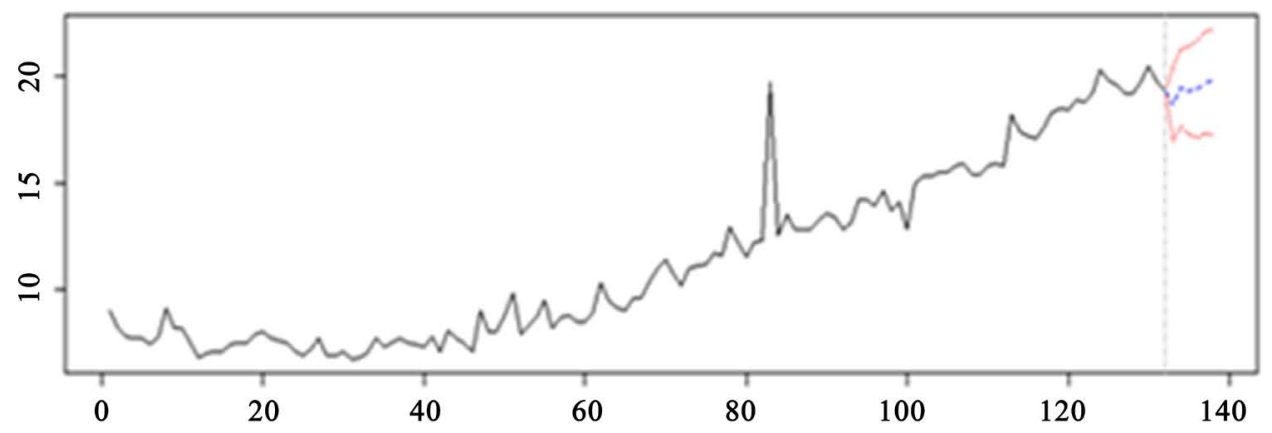

Figure 9. Forecast of electricity energy consumption for the first 6 months of 2019.

Table 7. Forecast of electricity energy consumption for the first 6 months of 2019.

\begin{tabular}{ccccc}
\hline Month/Year & Forecast & Lower & Upper & CI \\
\hline Jan/2019 & 23.93599 & 20.39870 & 20.39870 & 1.712706 \\
Feb/2019 & 23.95793 & 21.27485 & 21.27485 & 1.816915 \\
Mar/2019 & 24.27885 & 21.39319 & 21.39319 & 2.064332 \\
Apr/2019 & 26.18375 & 21.70369 & 21.70369 & 2.269934 \\
May/2019 & 22.09403 & 22.08486 & 22.08486 & 2.390834 \\
Jun/2019 & 23.0456 & 22.25576 & 22.25576 & 2.510155 \\
\hline
\end{tabular}


Table 8. Forecast accuracy.

\begin{tabular}{cccc}
\hline Month/Year & Observed EEC & Forecast & MAPE \\
\hline Jan/2019 & 22.88599 & 23.93599 & $4.54 \%$ \\
Feb/2019 & 23.05793 & 23.95793 & \\
Mar/2019 & 23.28885 & 24.27885 & \\
Apr/2019 & 24.83375 & 26.18375 & \\
\hline
\end{tabular}

\section{Conclusions}

This study examined the effects of climatic variables on electricity energy consumption in the Yendi municipality of Ghana. The following conclusions were drawn on the basis of the findings from this research:

1) Each of the different climatic variables contributes enormously in determining the amount of electricity energy to consume in the Yendi municipality of Ghana.

2) The increasing trend in electricity energy consumption observed, suggests that there would be substantial demand for electricity in Ghana and therefore policy makers, administrators, manufacturers and suppliers in the energy sector need to strategize to satisfy the electricity needs of the country as a whole.

\section{Conflicts of Interest}

The authors declare no conflicts of interest regarding the publication of this paper.

\section{References}

[1] Ighodaro, C.A.U. (2010) Co-Integration and Causality Relationship between Energy Consumption and Economic Growth: Further Empirical Evidence for Nigeria. Journal of Business Economics and Management, 11, 97-111. https://doi.org/10.3846/jbem.2010.05

[2] Mensah, G., et al. (2014) Energy Access Indicators and Trends in Ghana. Renewable and Sustainable Energy Reviews, 30, 317-323.

https://www.sciencedirect.com/science/article/pii/S1364032113007314

[3] Kumi, E.N. (2017) The Electricity Situation in Ghana: Challenges and Opportunities. Center for Global Development, Washington, D.C.

http://large.stanford.edu/courses/2018/ph241/owusu-adjapong1/docs/kumi.pdf

[4] Mickley, L.J., Jacob, D.J., Field, B.D. and Rind, D. (2004) Effects of Future Climate Change on Regional Air Pollution Episodes in the United States. Geophysical Research Letters, 31, L24103. https://doi.org/10.1029/2004GL021216

[5] Energy Department (2010) Annual Energy Outlook 2010: With Projections to 2035. Government Printing Office.

https://books.google.com.gh/books?hl=en\&lr=\&id=zNwmKz4APdoC\&oi=fnd\&pg= PA1\&dq=Kearney,+D.+(2010)+EIA\%E2\%80\%99s+Outlook+through $+2035+$ from + the + Annual + Energy + Outlook $+2010 . \&$ ots $=q$ Novemv1NO\&sig $=$ Q70iWsGU5hnld1e 7wUdT6tYUnqA\&redir esc $=y \# v=$ onepage\&q=Kearney\%2C\%20D.\%20(2010)\%20E IA\%E2\%80\%99s\%20Outlook\%20through\%202035\%20from\%20the\%20Annual\%20 Energy\%20Outlook\%202010.\&f=false 
[6] Nakicenovic, N., Grübler, A., Gaffin, S., Jung, T.T., Kram, T., Morita, T., Pither, H., Riahi, K., Schlesinger, M., Shukla, P.R., Van Vuuren, D., Davis, G., Michaelis, L., Swart, R. and Victor, N. (2003) IPCC SRES Revisited: A Response. Energy and Environment, 14, 187-214. https://doi.org/10.1260/095830503765184592

[7] Roth, M., Schilde, C., Lellig, P., Kwade, A. and Auernhammer, G.K. (2012) Colloidal Aggregates Tested via Nanoindentation and Quasi-Simultaneous 3D Imaging. European Physical Journal E, 35, Article No. 124.

https://doi.org/10.1140/epje/i2012-12124-8

[8] Ankamah, S., Nokoe, K.S. and Iddrisu, W.A. (2018) Modelling Trends of Climatic Variability and Malaria in Ghana Using Vector Autoregression. Malaria Research and Treatment, 2018, Article ID: 6124321. https://doi.org/10.1155/2018/6124321

[9] Dickey, D. and Fuller, W. (1979) Distribution of the Estimators for Autoregressive Time Series with a Unit Root. Journal of the American Statistical Association, 74, 427-431. https://doi.org/10.1080/01621459.1979.10482531

[10] Akaike, H. (1976) Canonical Correlation Analysis of Time Series and the Use of an Information Criterion. Mathematics in Science and Engineering, 126, 27-96. https://doi.org/10.1016/S0076-5392(08)60869-3

[11] Hannan, E.J. and Quinn, B.G. (1979) The Determination of the Order of an Autoregression. Journal of the Royal Statistical Society. Series B (Methodological), 41, 190-195. https://doi.org/10.1111/j.2517-6161.1979.tb01072.x

[12] Akaike, H. (1973) Maximum Likelihood Identification of Gaussian Autoregressive Moving Average Models. Biometrika, 60, 255-265.

https://doi.org/10.1093/biomet/60.2.255

[13] Schwarz, G. (1978) Estimating the Dimension of a Model. The Annals of Statistics, 6, 461-464. https://doi.org/10.1214/aos/1176344136

[14] Stockhammer, E. and Onaran, Ö. (2004) Accumulation, Distribution and Employment: A Structural VAR Approach to a Kaleckian Macro Model. Structural Change and Economic Dynamics, 15, 421-447. https://doi.org/10.1016/j.strueco.2003.07.002

[15] Lewis, C.D. (1997) Demand Forecasting and Inventory Control: A Computer Aided Learning Approach. Routledge, Abingdon-on-Thames. 